\title{
Mathematical modelling of p53 basal dynamics and DNA damage response
}

\author{
K.H. Chong ${ }^{\text {a }}$, S. Samarasinghe ${ }^{a}$ and D. Kulasiri ${ }^{\text {a }}$ \\ ${ }^{a}$ Centre for Advanced Computational Solutions (C-fACS) \\ Email: kething.chong@lincolnuni.ac.nz
}

\begin{abstract}
A gene that plays a crucial role in the regulation of cell life and death is the tumour suppressor gene $p 53$, which encodes protein $\mathrm{p} 53$. The p53 tumour suppressor protein is regarded as the "guardian of the genome", which is a transcription factor, that activates genes that result in DNA repair, cell cycle arrest, senescence (permanent cell cycle arrest) or apoptosis (programmed cell death) in response to various stress signals that could induce genetic instability. Recent individual cell studies have indicated that p53 activation is highly regulated in response to stress conditions and in unstressed normal proliferating cells. The aim of this research is to investigate the design principles behind the precise regulation of p53 activation. We develop a mathematical model using delay differential equations that incorporate the most recently found molecular interactions and genes regulated by p53, such as p53 activation of MdmX and Wip1, in the core regulation of p53 in normal proliferating cells and cells under DNA damage stress. We model the p53 core regulatory feedback mechanisms that control p53 levels. Experiments have shown that after DNA damage DNA double-strand breaks (DSBs) - p53 levels show a series of repeated pulses. Whereas in non-stressed conditions with intrinsic DNA damage, one or two spontaneous pulses (basal dynamics) were observed. Figure 1 shows a schematic diagram of the model hypothesis. We found that the core regulatory network consists of ATM, Mdm2, MdmX, Wip1 and p53, and it reproduced simulations consistent with the experimental findings. Our results show that the p53 spontaneous pulses are due to intrinsic DNA double strand breaks in normal proliferating cells. Local parameter sensitivity analysis identified Wip1 as the major component that controlled the period of p53 oscillations. Despite its simplicity, our model is a mechanistic model that presents a dynamic hypothesis of molecular interactions that control p53 activation.
\end{abstract}

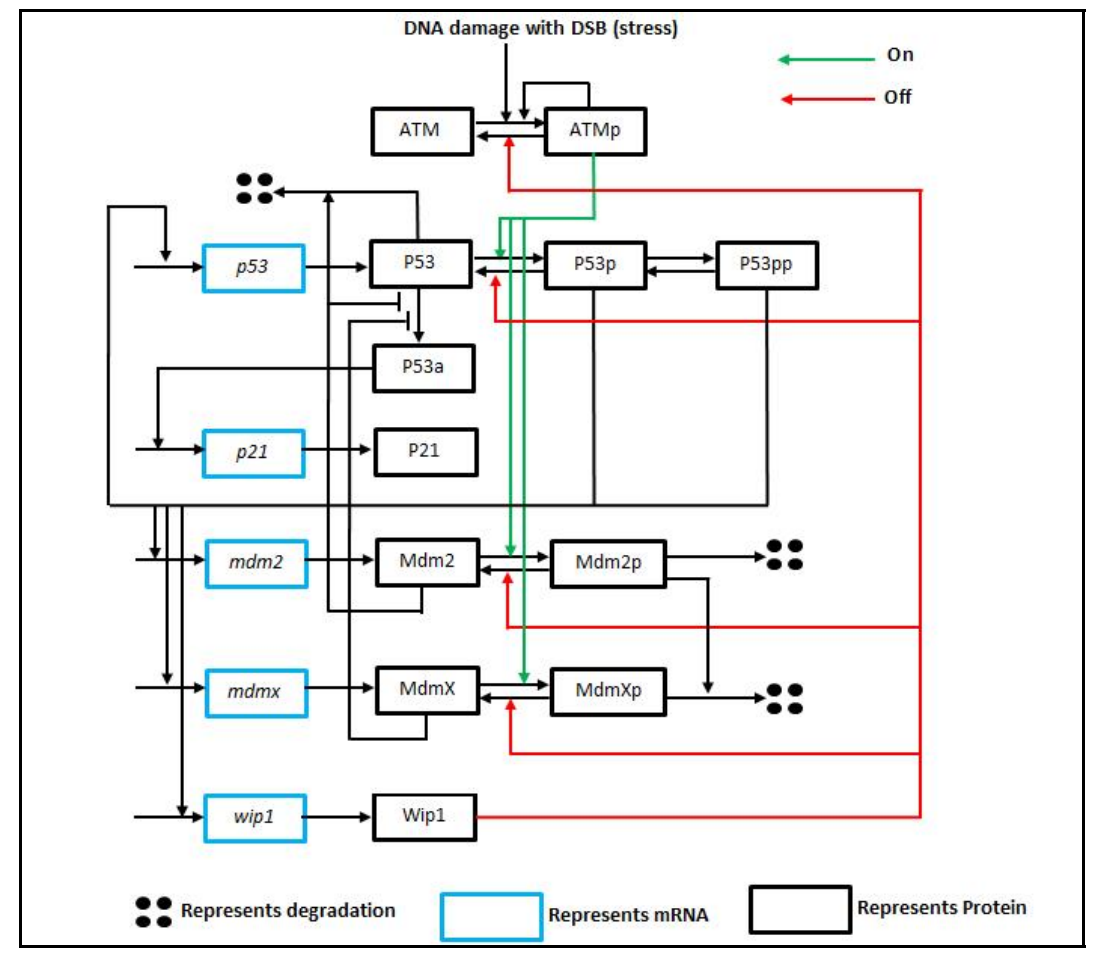

Figure 1. A schematic diagram of the proposed model.

Keywords: P53 basal dynamics, DNA damage response, Mathematical models, Mdm2, Spontaneous pulses 


\section{INTRODUCTION}

Tumour suppressor $\mathrm{p} 53$ plays a critical role in protecting our genome from mutations that can lead to cancer. P53 is a major node in the DNA damage response and is one of the most intensely studied proteins due to its function as a transcription factor that controls the expression of over hundreds of genes. The genes activated by p53 can result in DNA damage repair, cell cycle arrest, senescence (permanent cell cycle arrest) or apoptosis (programmed cell death). The levels and the activities of p53 are highly regulated in cells. This was demonstrated by a study using fluorescent protein fused to p53 promoter and measuring p53 endogenous protein and the fluorescent reporter in individual cells after exposure to gamma-irradiation (Lahav et al. 2004). Through the study of this genetically constructed system, the quantitative individual cell dynamics of p53 after DNA damage showed a series of pulses that relates to the level of damage. A subset of the genes activated by $\mathrm{p} 53$, such as $\mathrm{Mdm} 2, \mathrm{MdmX}$ and Wip1, are negative feedback regulators that modulate $\mathrm{p} 53$ levels and transcription activity.

Recently, under non-stressed conditions, the basal dynamics of $\mathrm{p} 53$ with spontaneous pulses was revealed by another study (Loewer et al. 2010) and these remarkable results showed that p53 is sensitive to stress signals under stressed conditions and tolerant to intrinsic DNA damage. These experimental findings posed a challenge to modelers to construct a model(s) for the mechanism behind these unexpected results.

A mathematical model, if well-constructed, can give insights into the mechanism of the p53 regulation. Sun et al. (2011) have attempted to model the basal dynamics using stochastic model, but there is still lacking a deterministic model. In this paper, we extend an existing deterministic model from (Sun et al. 2011) that does not capture p53 basal dynamics, and investigate the design principles of the gene regulation circuit that modulates p53 basal dynamics and DNA damage response. No deterministic model has been built to study the p53 system that produces both spontaneous pulses for non-stressed conditions and series of pulses for stressed conditions and we propose to address this here; we describe the constructed model incorporating the core regulators (Mdm2, MdmX and Wip1) and simulation results that are qualitatively consistent with the experimental results reported by Loewer et al. (2010). Our model analyses give us insight into the key parameters that controlled by p53 oscillations, and may provide useful strategy in drug design.

\section{MODEL ASSUMPTIONS}

The proposed mathematical model is a deterministic model with delay differential equations, which extends the deterministic model from Sun et al. (2011) and the model assumptions are illustrated in a schematic diagram shown in Figure 1. For constructing a more accurate model, a few components are added and the key differences compared to Sun et al. model are: 1) MdmX is included; 2) p53 positive auto-regulation is included; 3) p53-Mdm2, Mdm2-MdmX and p53-MdmX complexes are represented; 4) Mdm2 and MdmX inhibit p53 acetylation. When cells are exposed to stress, for example gamma-irradiation, it causes DNA double-strand breaks (DSBs). The DSB is the input into the model. The DSBs activate the protein kinase, ataxia telangiectasia mutated (ATM) and these stress signals are further amplified by ATM intermolecular auto-phosphorylation (see Eqn. (6) first and second terms, respectively). The DSBs caused ATM phosphorylation results in a cascade of phosphorylation activities that activates p53 (Figure 1 green arrows, turn on p53) (Cheng and Chen 2010). Firstly, ATM phosphorylation of Mdm2 prevents the ability of Mdm2 binding to $\mathrm{p} 53$ and degradation of $\mathrm{p} 53$. At the same time, Mdm2 switches the target of ubiquitination from p53 to itself and MdmX, and thus facilitates p53 activation. Secondly, ATM phosphorylation of p53 disrupts Mdm2 binding and stabilizes p53. Finally, ATM also phosphorylates MdmX. Phosphorylation of MdmX enhances binding, ubiquitination and degradation by Mdm2 (Cheng and Chen 2010).

Phosphorylated p53 (P53p) can be further phosphorylated at different sites, represented by P53pp. It is assumed that both P53p and P53pp activate the transcription of p53 itself, $m d m 2, m d m x$ and Wip1. We adopted the transcriptional time delay of $30 \mathrm{~min}$ and translation/translocation delay of $10 \mathrm{~min}$ proposed by Ma et al. (Ma et al. 2005). The up-regulation of Wip1 plays a role in modulating ATM-dependent signalling pathway, and attenuating the $\mathrm{p} 53$ response. Wip1 function as a phosphatase that dephosphorylates ATM, p53, Mdm2, and MdmX (Fig. 1 red arrows, turn off p53) (Wade et al. 2010). Wip1 reverses the stress signal protein ATMp and p53p to un-phosphorylated form, resetting ATM and p53 to non-active state. Thus, Wip1 creates a p53 negative feedback mechanism that attenuates the stress signal and p53 activation. Moreover, Wip1 dephosphorylates Mdm2 and MdmX.

MdmX inhibits p53 mainly by forming a p53-MdmX complex (Cheng and Chen 2010), and this is represented by a reversible reaction of p53-MdmX complex (C3) formation and dissociation (Fig. 2). MdmX also regulates p53 levels by modulating $\mathrm{Mdm} 2$ levels and E3 ligase activity towards p53 ubiquitination and degradation through the heterodimers $\operatorname{Mdm} 2-\operatorname{MdmX}(\mathrm{C} 2)$, and this reversible reaction is represented by the 
reaction of Mdm2-MdmX complex (C2) formation and dissociation. The p53-Mdm2 complex (C1) formation and dissociation is also included in this model to represent the binding and unbinding between Mdm2 and p53 protein molecules.

Moreover, Mdm2 is assumed to inhibit p53 activity by repressing p53 acetylation. This is based on the experimental results that demonstrated that Mdm2 suppresses p300/CBP acetylation of p53, where p300 and CBP are acetyltransferases that function as co-activators to promote p53 acetylation. Similarly, MdmX was also reported to suppress p300/CBP acetylation of p53 and both Mdm2 and MdmX inhibition of p53 acetylation are represented by a dashed arrow in Figure 1. These inhibitions by Mdm2 and MdmX of p53 acetylation were modelled as competitive inhibition reactions (See Eqn. 10 below). Acetylated p53 (P53a) is assumed to activate $p 21$, a gene that encodes protein $\mathrm{P} 21$, which acts as a cyclin-dependent kinase inhibitor to arrest cell cycle, inhibits Cyclin E/cdk2 kinase and causes G1 arrest (Kastan and Bartek 2004). For clarity, a few model interactions are not shown in Figure 1 and Figure 2. These interactions are listed below:

1. $\mathrm{P} 21$ protein degradation is mediated by heterodimer $\mathrm{C} 2$ (see Eqn. (11) last term)

2. DSB induces Mdm2 protein degradation (see Eqn. (12) second last term)

3. Mdm2p promotes auto-ubiquitination and degradation of Mdm2 (see Eqn. (12) last term)

Most of the reactions are represented by mass action kinetics. The p53-dependent gene transcription activation is model by a Hill function with Hill coefficient of 4 . The equations of the model are given below:

Equations for mRNAs:

$$
\begin{aligned}
& \mathrm{d} p 53 / \mathrm{dt}=\mathrm{S}_{\mathrm{p} 53}+\mathrm{e}_{5} \cdot\left(P 53 p\left(t-\tau_{5}\right)+P 53 p p\left(t-\tau_{5}\right)\right)^{4} /\left[\mathrm{K}_{\mathrm{p} 53}{ }^{4}+\left(P 53 p\left(t-\tau_{5}\right)+P 53 p p\left(t-\tau_{5}\right)\right)^{4}\right]-\delta_{\mathrm{p} 53} \cdot p 53 \\
& \mathrm{~d} p 21 / \mathrm{dt}=\mathrm{e}_{4} \cdot P 53 a\left(t-\tau_{4}\right)^{4} /\left[\mathrm{K}_{\mathrm{p} 21}{ }^{4}+P 53 a\left(t-\tau_{4}\right)^{4}\right]-\delta_{\mathrm{p} 53} \cdot p 21 \\
& \mathrm{~d} m d m 2 / \mathrm{dt}=\mathrm{S}_{\mathrm{mdm} 2}+\mathrm{e}_{1} \cdot\left(P 53 p\left(t-\tau_{1}\right)+P 53 p p\left(t-\tau_{1}\right)\right)^{4} /\left[\mathrm{K}_{\mathrm{m}}{ }^{4}+\left(P 53 p\left(t-\tau_{1}\right)+P 53 p p\left(t-\tau_{1}\right)\right)^{4}\right]-\delta_{\mathrm{mdm} 2} \cdot m d m 2 \\
& \mathrm{~d} m d m x / \mathrm{dt}=\mathrm{S}_{\mathrm{mdmx}}+\mathrm{e}_{3} \cdot\left(P 53 p\left(t-\tau_{3}\right)+P 53 p p\left(t-\tau_{3}\right)\right)^{4} /\left[\mathrm{K}_{\mathrm{x}}{ }^{4}+\left(P 53 p\left(t-\tau_{3}\right)+P 53 p p\left(t-\tau_{3}\right)\right)^{4}\right]-\delta_{\mathrm{mdmx}} \cdot m d m x \\
& \mathrm{~d} w i p 1 / \mathrm{dt}=\mathrm{S}_{\mathrm{wip} 1}+\mathrm{e}_{2} \cdot\left(P 53 p\left(t-\tau_{2}\right)+P 53 p p\left(t-\tau_{2}\right)\right)^{4} /\left[\mathrm{K}_{\mathrm{w}}{ }^{4}+\left(P 53 p\left(t-\tau_{2}\right)+P 53 p p\left(t-\tau_{2}\right)\right)^{4}\right]-\delta_{\text {wip } 1} \cdot w i p 1
\end{aligned}
$$

Equations for Proteins:

$$
\begin{aligned}
& \mathrm{d} A T M p / \mathrm{dt}=\mathrm{k}_{\mathrm{DSB}} \cdot \mathrm{DSB} /\left(\mathrm{DSB}+\mathrm{K}_{\mathrm{DSB}}\right) \cdot \mathrm{ATM}+\mathrm{k}_{\mathrm{auto}} \cdot A T M p \cdot \mathrm{ATM}-\mathrm{k}_{\mathrm{basal}} \cdot A T M p-\mathrm{k}_{\mathrm{wip} 4} \cdot W i p 1 \cdot A T M p \\
& \mathrm{~d} P 53 / \mathrm{dt}=\mathrm{r}_{\mathrm{p} 53} \cdot p 53\left(t-\tau_{6}\right)-\mu_{\mathrm{p} 53} \cdot P 53-\mathrm{k}_{1} \cdot C 1-\mathrm{k}_{2} \cdot P 53 \cdot C 2-\mathrm{k}_{\mathrm{atm} 1} \cdot A T M p \cdot P 53+\mathrm{k}_{\mathrm{wip} 1} \cdot P 53 p \cdot W i p 1-\mathrm{k}_{\mathrm{f} 1} \cdot M d m 2 \cdot P 53 \\
& +\mathrm{k}_{\mathrm{b} 1} \cdot C 1-\mathrm{k}_{\mathrm{f3}} \cdot M d m X \cdot P 53+\mathrm{k}_{\mathrm{b} 3} \cdot C 3 \\
& \mathrm{~d} P 53 p / \mathrm{dt}=\mathrm{k}_{\mathrm{atm} 1} \cdot A T M p \cdot P 53-\mathrm{k}_{\mathrm{wip} 1} \cdot P 53 p \cdot W i p 1-\mathrm{k}_{\mathrm{phos}} \cdot P 53 p+\mathrm{k}_{\mathrm{dephos}} \cdot P 53 p p-\mu_{\mathrm{p} 53 \mathrm{p}} \cdot P 53 p \\
& \mathrm{~d} P 53 p p / \mathrm{dt}=\mathrm{k}_{\mathrm{phos}} \cdot P 53 p-\mathrm{k}_{\mathrm{dephos}} \cdot P 53 p p-\mu_{\mathrm{p} 53 \mathrm{pp}} \cdot P 53 p p \\
& \mathrm{~d} P 53 a / \mathrm{dt}=\mathrm{V}_{\max 1} \cdot P 53 /\left[P 53+\mathrm{K}_{\mathrm{m} 1}+\mathrm{K}_{\mathrm{m} 1} \cdot M d m 2 / \mathrm{K}_{\mathrm{i} 1}\right]+\mathrm{V}_{\max 2} \cdot P 53 /\left[P 53+\mathrm{K}_{\mathrm{m} 2}+\mathrm{K}_{\mathrm{m} 2} \cdot M d m X / \mathrm{K}_{\mathrm{i} 2}\right]-\mu_{\mathrm{p} 53 \mathrm{a}} \cdot P 53 a(10) \\
& \mathrm{d} P 21 / \mathrm{dt}=\mathrm{r}_{\mathrm{p} 21} \cdot p 21\left(t-\tau_{7}\right)-\mu_{\mathrm{p} 21} \cdot P 21-\mathrm{k}_{\mathrm{d} 21} \cdot C 2 \cdot P 21 \\
& \mathrm{~d} M d m 2 / \mathrm{dt}= \\
& \mathrm{r}_{\mathrm{mdm} 2} \cdot m d m 2\left(t-\tau_{8}\right)-\mu_{\mathrm{mdm} 2} \cdot M d m 2-\mathrm{k}_{\mathrm{atm} 2} \cdot A T M p \cdot M d m 2-\mathrm{k}_{\mathrm{f} 1} \cdot M d m 2 \cdot P 53+\mathrm{k}_{\mathrm{b} 1} \cdot C 1-\mathrm{k}_{\mathrm{f} 2} \cdot M d m 2 \cdot M d m X+\mathrm{k}_{\mathrm{b} 2} \cdot C 2 \\
& +\mathrm{k}_{\mathrm{wip} 2} \cdot M d m 2 p \cdot W i p 1-\mathrm{k}_{\mathrm{d} 22} \cdot \mathrm{DSB} /(\mathrm{J}+\mathrm{DSB}) \cdot M d m 2-\mathrm{k}_{4} \cdot M d m 2 p \cdot M d m 2 \\
& \mathrm{~d} M d m 2 p / \mathrm{dt}=\mathrm{k}_{\mathrm{atm} 2} \cdot A T M p \cdot M d m 2-\mathrm{k}_{\mathrm{wip} 2} \cdot M d m 2 p \cdot W i p 1-\mu_{\mathrm{mdm} 2 \mathrm{p}} \cdot M d m 2 p
\end{aligned}
$$




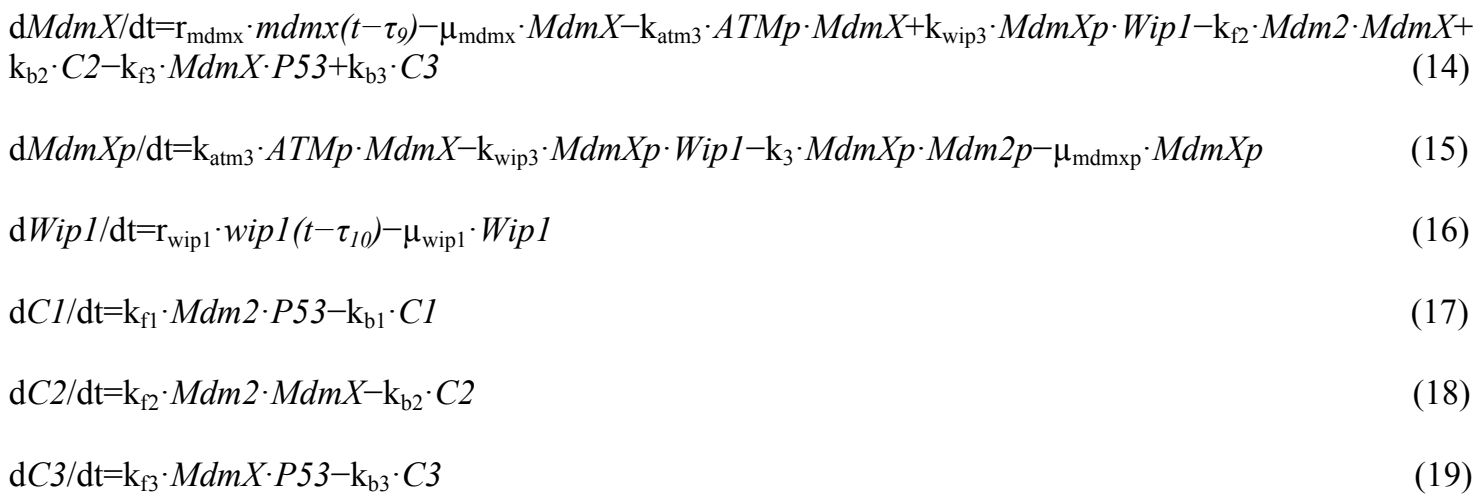

We assumed that the ATM level is constant at $1 \mu \mathrm{M}$ as the expression of ATM is relatively constant (Kastan and Bartek 2004). Thus, the concentration for ATM is given by: $A T M=1-A T M p$

\section{PARAMETERS ESTIMATION}

Lahav et al. (2004) and Loewer et al. (2010) experimental data for p53 protein were measured by fluorescent reporter normalized arbitrary to Therefore, we calibrated the model parameters, using the try-and-error method, to obtain a reasonable

simulation results for the p53 protein levels in the range of 0.06 to $0.5 \mu \mathrm{M}$, which is the range of p53 protein measurements made by $\mathrm{Ma}$ et al. (2005). The estimated parameters are shown in Table 1 and the initial conditions used are shown in Table 2.

\section{Table 1 Parameter values}

Parameter Meaning

1. $\mathrm{S}_{\mathrm{p} 53}$ Basal production rate of P53 mRNA

2. $\mathrm{s}_{\mathrm{mdm} 2}$ Basal production rate of $\mathrm{Mdm} 2 \mathrm{mRNA}$

3. $s_{m d m x}$ Basal production rate of MdmX mRNA

4. $\mathrm{S}_{\text {wip } 1}$ Basal production rate of Wip1 mRNA

5. $\mathrm{e}_{1} \quad \mathrm{P} 53$-dependent $m d m 2$ transcription rate

6. $\mathrm{e}_{2} \quad$ P53-dependent Wipl transcription rate

7. $\mathrm{e}_{3} \quad \mathrm{P} 53$-dependent $m d m x$ transcription rate

8. $\mathrm{e}_{4} \quad$ P53-dependent $p 21$ transcription rate

9. $\mathrm{e}_{5} \quad \mathrm{P} 53$-dependent $p 53$ transcription rate

10. $\mathrm{K}_{\mathrm{p} 53}$ Michaelis constant of $\mathrm{p} 53$-dependent $p 53$ transcription

11. $\mathrm{K}_{\mathrm{p} 21}$ Michaelis constant of $\mathrm{p} 53$-dependent $p 21$ transcription

12. $\mathrm{K}_{\mathrm{m}} \quad$ Michaelis constant of p53-dependent $m d m 2$ transcription

13. $\mathrm{K}_{\mathrm{x}} \quad$ Michaelis constant of p53-dependent $m d m x$ transcription

14. $\mathrm{K}_{\mathrm{w}} \quad$ Michaelis constant of $\mathrm{p} 53$-dependent Wip1 transcription

15. $\delta_{\mathrm{p} 53}$ Degradation rate of P53 mRNA

16. $\delta_{\mathrm{p} 21}$ Degradation rate of $\mathrm{P} 21 \mathrm{mRNA}$

17. $\delta_{\mathrm{mdm} 2}$ Degradation rate of Mdm2 mRNA

18. $\delta_{\text {mdmx }}$ Degradation rate of MdmX mRNA

19. $\delta_{\text {wip } 1}$ Degradation rate of Wip1 mRNA

20. $r_{p 53}$ Translation rate of P53

21. $r_{\mathrm{p} 21}$ Translation rate of $\mathrm{P} 21$

22. $r_{\mathrm{mdm} 2}$ Translation rate of $\mathrm{Mdm} 2$

23. $r_{m d m x}$ Translation rate of MdmX

24. $r_{\text {wip } 1}$ Translation rate of Wip1

25. $\mu_{\mathrm{p} 53}$ Basal degradation rate of P53

26. $\mu_{\mathrm{p} 53 \mathrm{p}}$ Basal degradation rate of P53p

27. $\mu_{\mathrm{p} 53 \mathrm{pp}}$ Basal degradation rate of P53pp

28. $\mu_{\mathrm{p} 53 \mathrm{a}}$ Basal degradation rate of P53a

29. $\mu_{\mathrm{p} 21} \quad$ Basal degradation rate of $\mathrm{P} 21$

30. $\mu_{\mathrm{mdm} 2}$ Basal degradation rate of $\mathrm{Mdm} 2$

31. $\mu_{\mathrm{mdmx}}$ Basal degradation rate of $\mathrm{MdmX}$

32. $\mu_{\text {wip } 1}$ Basal degradation rate of Wip1

33. $\mu_{\mathrm{mdm} 2 \mathrm{p}}$ Degradation rate of Mdm2p

34. $\mu_{\text {mdmxp }}$ Degradation rate of MdmXp

35. $\mathrm{k}_{1} \quad \mathrm{Mdm} 2$-dependent P53 degradation through $\mathrm{C} 1$

36. $\mathrm{k}_{2} \quad \mathrm{C} 2(\mathrm{Mdm} 2-\mathrm{MdmX})$-dependent P53 degradation

37. $\mathrm{k}_{3} \quad \mathrm{Mdm} 2$-dependent MdmX degradation

38. $\mathrm{k}_{4} \quad \mathrm{Mdm} 2$-dependent Mdm2 degradation (auto-ubiquitination)

39. $\mathrm{k}_{\mathrm{atm} 1}$ ATM induced P53 phosphorylation

40. $\mathrm{k}_{\mathrm{atm} 2}$ ATM induced Mdm2 phosphorylation

41. $\mathrm{k}_{\mathrm{atm} 3}$ ATM induced MdmX phosphorylation

42. $\mathrm{k}_{\text {wip1 }} \quad$ Wip1 induced P53p dephosphorylation

43. $\mathrm{k}_{\text {wip2 }}$ Wip1 induced Mdm2p dephosphorylation

44. $\mathrm{k}_{\text {wip3 }}$ Wip1 induced MdmXp dephosphorylation

45. $\mathrm{k}_{\text {wip4 }}$ Wip1 induced ATMp dephosphorylation 


\begin{tabular}{|c|c|c|c|}
\hline Parameter & Meaning & Value & Unit \\
\hline 46. $\mathrm{k}_{\mathrm{DSB}}$ & DSB induced ATM activation rate & 0.0005 & $\min ^{-1}$ \\
\hline 47. DSB & Double Strand Break (300 approximately $10 \mathrm{~Gy} \gamma$-irradiation) & 300 & Unit of 1 \\
\hline 48. $\mathrm{K}_{\mathrm{DSB}}$ & Activation scaling parameter & 200 & Unit of 1 \\
\hline 49. $\mathrm{k}_{\text {auto }}$ & ATM auto-activation & 0.07 & $\mu \mathrm{M}^{-1} \min ^{-1}$ \\
\hline $50 . \mathrm{k}_{\text {basal }}$ & ATMp basal inactivation rate & 0.02 & $\min ^{-1}$ \\
\hline 51. $\mathrm{k}_{\mathrm{fl}}$ & P53-Mdm2 complex association rate & 552 & $\mu \mathrm{M}^{-1} \min ^{-1}$ \\
\hline 52. $\mathrm{k}_{\mathrm{f} 2}$ & Mdm2-MdmX complex association rate & 600 & $\mu \mathrm{M}^{-1} \min ^{-1}$ \\
\hline 53. $\mathrm{k}_{\mathrm{f3}}$ & P53-MdmX complex association rate & 552 & $\mu \mathrm{M}^{-1} \min ^{-1}$ \\
\hline 54. $\mathrm{k}_{\mathrm{b} 1}$ & P53-Mdm2 complex dissociation rate & 123.6 & $\min ^{-1}$ \\
\hline $55 . \mathrm{k}_{\mathrm{b} 2}$ & Mdm2-MdmX complex dissociation rate & 18 & $\min ^{-1}$ \\
\hline 56. $\mathrm{k}_{\mathrm{b} 3}$ & P53-MdmX complex dissociation rate & 123.6 & $\min ^{-1}$ \\
\hline 57. $\mathrm{k}_{\text {phos }}$ & P53 further phosphorylation by other enzymes (e.g. Chk2) & 0.3 & $\min ^{-1}$ \\
\hline 58. $\mathrm{k}_{\text {denhos }}$ & P53 further dephosphorylated by other enzymes (e.g. PP2A ) & 0.05 & $\min ^{-1}$ \\
\hline 59. $V_{\max 1}$ & The maximal rate & 0.0001 & $\mu \mathrm{M} \min ^{-1}$ \\
\hline 60. $V_{\max 2}$ & The maximal rate & 0.001 & $\mu \mathrm{M} \min ^{-1}$ \\
\hline 61. $\mathrm{K}_{\mathrm{m} 1}$ & The half-saturation constant & 0.000025 & $\mu \mathrm{M}$ \\
\hline 62. $\mathrm{K}_{\mathrm{m} 2}$ & The half-saturation constant & 0.5 & $\mu \mathrm{M}$ \\
\hline 63. $\mathrm{K}_{\mathrm{i} 1}$ & The dissociation constant for the enzyme-inhibitor (e.g. p300-Mdm2) & 0.00001 & $\mu \mathrm{M}$ \\
\hline 64. $\mathrm{K}_{\mathrm{i} 2}$ & The dissociation constant for the enzyme-inhibitor (e.g. p300-MdmX) & 0.0001 & $\mu \mathrm{M}$ \\
\hline $65 . \mathrm{k}_{\mathrm{d} 21}$ & $\mathrm{C} 2$ induced $\mathrm{P} 21$ degradation & 0.5 & $\mu \mathrm{M}^{-1} \min ^{-1}$ \\
\hline 66. J & Degradation scaling parameter & 0.2 & Unit of 1 \\
\hline 67. $\mathrm{k}_{\mathrm{d} 22}$ & DSB induced Mdm2 degradation & 0.01 & $\min ^{-1}$ \\
\hline 68. $\tau_{1}$ & $m d m 2$ transcription delay & 30 & $\min$ \\
\hline 69. $\tau_{2}$ & wip1 transcription delay & 30 & $\min$ \\
\hline 70. $\tau_{3}$ & $m d m x$ transcription delay & 30 & $\min$ \\
\hline 71. $\tau_{4}$ & $p 21$ transcription delay & 30 & $\min$ \\
\hline 72. $\tau_{5}$ & $p 53$ transcription delay & 30 & $\min$ \\
\hline 73. $\tau_{6}$ & P53 translational delay & 10 & $\min$ \\
\hline 74. $\tau_{7}$ & P21 translational delay & 10 & $\min$ \\
\hline 75. $\tau_{8}$ & Mdm2 translational delay & 10 & $\min$ \\
\hline 76. $\tau_{9}$ & MdmX translational delay & 10 & $\min$ \\
\hline 77. $\tau_{10}$ & Wip1 translational delay & 10 & $\min$ \\
\hline 78. $\mathrm{n}$ & Hill coefficient & 4 & \\
\hline
\end{tabular}

\section{SIMULATION RESULTS}

\subsection{P53 oscillatory behavior in stressed conditions}

We modelled the stressed conditions by setting the DSB equal to 300 corresponding to 10 Grays of gamma-irradiation imposed on cells. The simulation results for p53 total protein levels are shown in Figure 3 (a), where p53 levels (blue) are in a series of pulses with fixed amplitude and duration. The period of the p53 oscillations is 5.8 hours which is consistent with the experimental results of 4-7 hours from Lahav et al. (2004) and Loewer et al. (2010). We modelled p21 mRNA as a model output as Sun et al. (2011) and the p21 mRNA levels are shown in Figure 3 (c). The p21 mRNA levels (green) increases over time and it shows that p21 is induced under stressed conditions, which is qualitatively consistent with Loewer et al. experimental observations of p21 induction (Loewer et al., 2010 Fig 5D). Simulation results indicates that p21 induction is sensitive to DNA damage response under stressed conditions and results in cell cycle arrest to prevent duplication of damaged DNA template.

\begin{tabular}{llc}
\multicolumn{2}{l}{ Table 2 Initial conditions } \\
\hline Molecular species & Meaning & Value $(\boldsymbol{\mu M})$ \\
\hline p53 & P53 mRNA & 0.05 \\
p21 & P21 mRNA & 0.05 \\
mdm2 & Mdm2 mRNA & 0.05 \\
mdmx & MdmX mRNA & 0.01 \\
wip1 & Wip1 mRNA & 0.04 \\
ATMp & Phosphorylated ATM & 0 \\
P53 & P53 protein & 0.0258 \\
P53p & Phosphorylated P53 protein & 0 \\
P53pp & Multiple Phosphorylated P53 protein & 0 \\
P53a & Acetylated P53 protein & 0.01 \\
P21 & P21 protein & 0.01 \\
Mdm2 & Mdm2 protein & 0.15 \\
Mdm2p & Phosphorylated Mdm2 protein & 0.0178 \\
MdmX & MdmX protein & 0.08 \\
MdmXp & Phosphorylated MdmX protein & 0.01 \\
Wip1 & Wip1 protein & 0 \\
C1 & P53-Mdm2 complex & 0.06 \\
C2 & Mdm2-MdmX complex & 0.05 \\
C3 & P53-MdmX complex & 0.05 \\
\hline
\end{tabular}
. 


\subsection{P53 basal dynamics in non-stressed conditions}

For the non-stressed conditions or p53 basal dynamics, we set the DSB to a low number three or one to mimic the non-stressed conditions as in Figure 3 (b) and Figure 3 (d), respectively. The simulation results show two spontaneous pulses when $\mathrm{DSB}=3$ and one pulse when $\mathrm{DSB}=1$. The spontaneous pulses did not induce p21 mRNA as shown in Figure 3 (d), where p21 mRNA stayed at low basal levels under non-stressed conditions. These p53 basal dynamics of spontaneous pulses and p21 non-induction are in good agreement with Loewer et al. (2010) experimental findings (Loewer et al., 2010 Fig 5E).

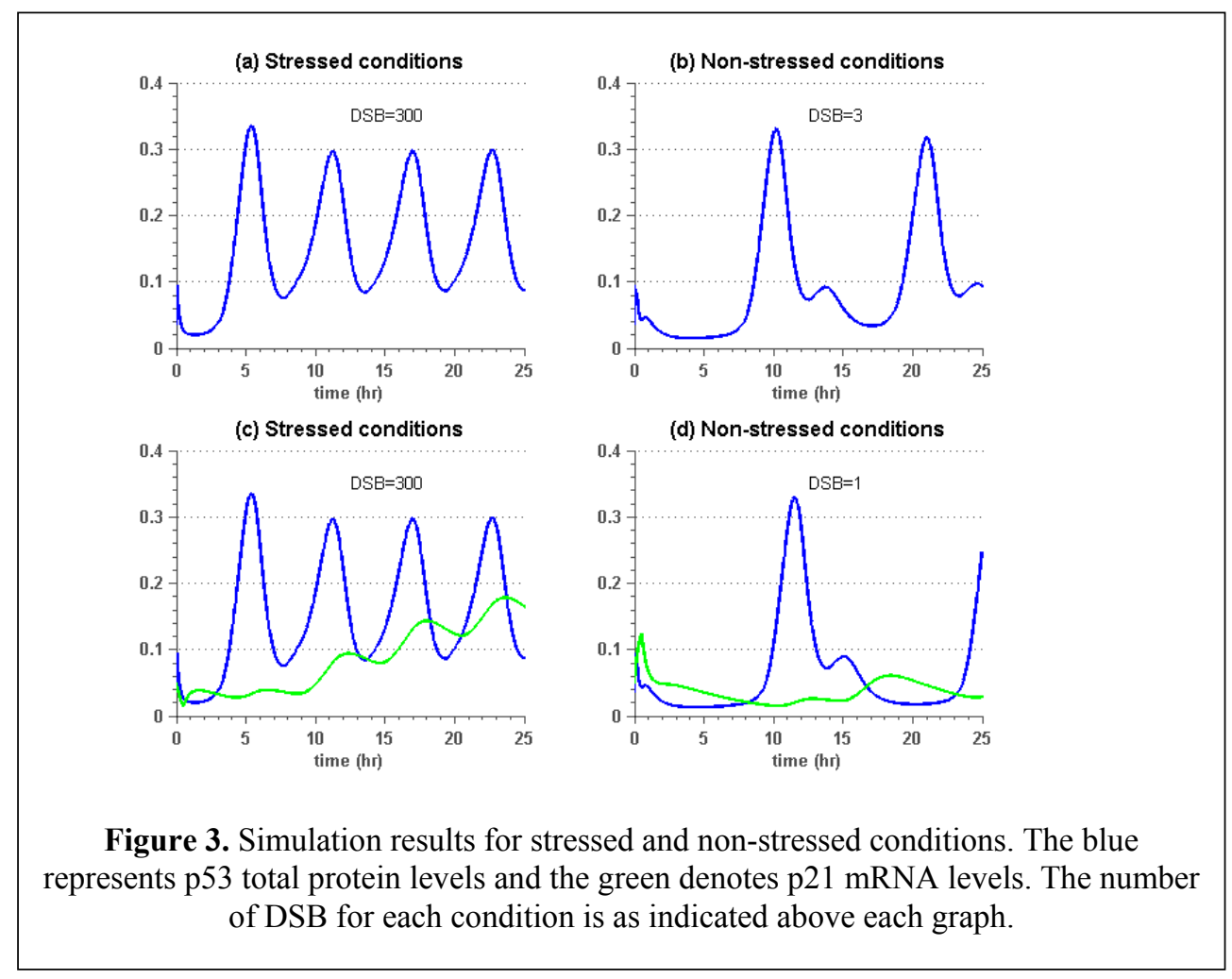

\section{LOCAL PARAMETER SENSITIVITY ANALYSIS}

In the modelling process, parameter values were estimated and it involves uncertainty in these estimated parameter values. This is unavoidable since most of the parameter values are unavailable or not measured in experiments. Thus, parameter sensitivity analysis is required to investigate which parameters are the most important factors that affect p53 behaviour. In the literature, period and amplitude of p53 oscillations are measurements of the model output for sensitivity analysis. Here, we chose period of oscillations as the output for local parameter sensitivity analysis. It was performed by increasing (or decreasing) one of the parameters by $20 \%$ from its standard parameter value while holding the other parameter values fixed at the standard levels. The estimates of the period of oscillation of total p53 levels were obtained by using spectrum resampling technique (Costa et al. 2013). This technique uses bootstrapping of spectral estimates to estimate the period of an oscillatory time series data. The results of the local sensitivity analysis are shown in Figure

Table 3 Key parameters

\begin{tabular}{|l|l|c|}
\hline $\begin{array}{l}\text { Parameter } \\
\text { Index no. }\end{array}$ & Symbol & Meaning \\
\hline 32 & $\mu_{\text {wip1 }}$ & Wip1 protein degradation rate \\
\hline 69 & $\tau_{2}$ & wip1 transcription delay \\
\hline 19 & $\delta_{\text {wip } 1}$ & wip1 mRNA degradation rate \\
\hline 49 & $\mathrm{k}_{\text {auto }}$ & ATM auto-activation rate \\
\hline
\end{tabular}

4.

Some key parameters that have major influence on the p53 period were identified. These parameters are listed in Table 3.

The local sensitivity analysis shows that period of p53 oscillations is robust to perturbation with $5.8 \pm 0.2$ hours. Oscillations are lost and p53 stayed at low basal levels only for lowering the nominal parameter value (as in Table 1) for each of $\delta_{\text {wip } 1}, \mu_{\text {wip } 1}$ and $k_{\text {auto }}$ by fifty percent (data not shown). 


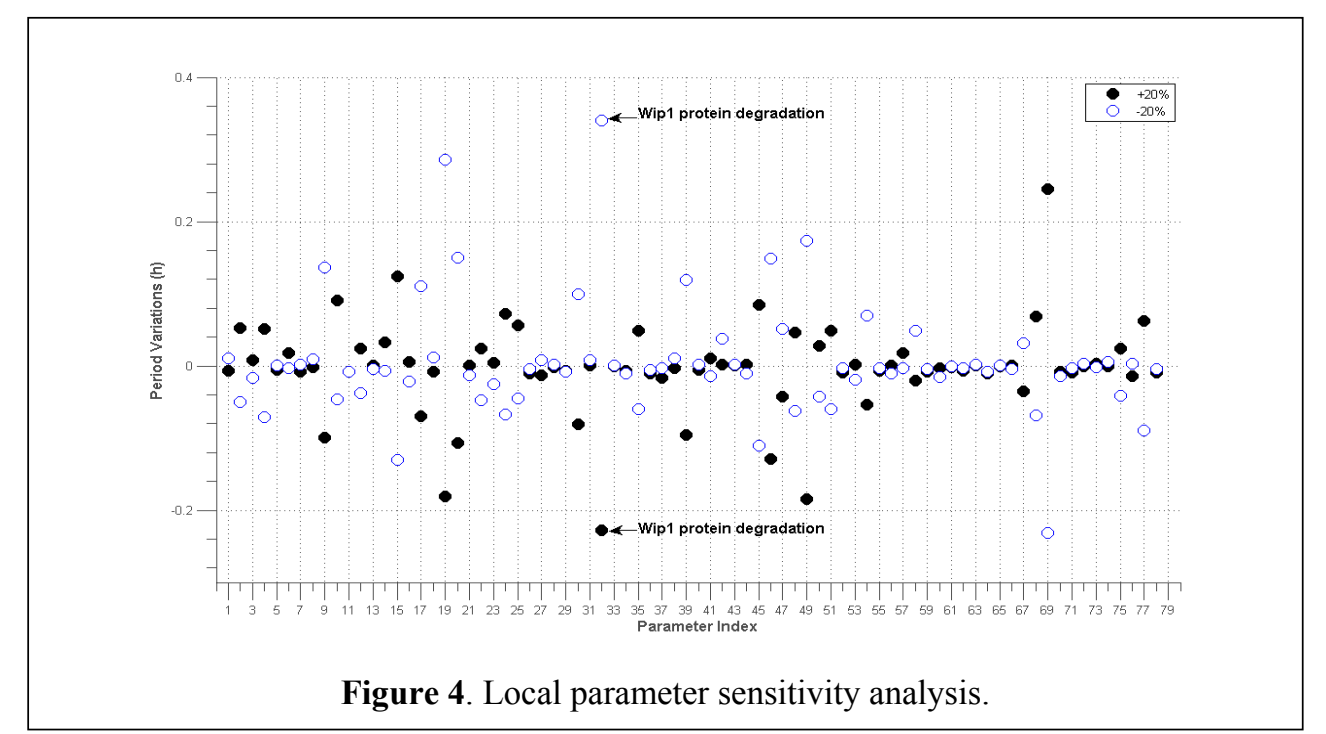

\section{DISCUSSION AND CONCLUSIONS}

In this paper, we proposed a deterministic model of p53 basal dynamics and DNA damage response under stressed conditions. The simulation results for the stressed conditions, where we set the DSB to 300, produce a series of pulses with fixed amplitude and period of 5.8 hours. However, under non-stressed conditions we assumed the DSB is low, three or one. These low DSBs are realistic assumptions for intrinsic average DSB as measured by ( $\mathrm{Yu}$ et al. 2006). Our model simulation results suggest that p53 spontaneous pulses are due to intrinsic DSB. The simulation for the p21 mRNA shows that it is induced under stressed conditions and not induced under non-stressed conditions, which are consistent with Loewer et al. (2010) experimental observations.

Our model incorporating three negative regulators (Mdm2, MdmX and Wip1) of p53, two positive feedback loops (ATM auto-activation and p53 auto-regulation) and the interactions of p53, Mdm2 and MdmX; according to the model structure, we have proposed a plausible model for p53 regulation under normal and stressed conditions. Finally, local parameter sensitivity analysis has identified some important parameters that control the period of p53 oscillations, notably Wip1 protein and mRNA degradation rate, Wip1 transcription delay and ATM auto-activation rate. Our model analyses lead us to conclude that these parameters may be useful target(s) in drug design to modulate the p53 oscillations and function.

\section{REFERENCES}

Cheng, Q. and Chen, J. (2010). Mechanism of p53 stabilization by ATM after DNA damage, Cell Cycle 9: 472-478.

Costa, M.J., Finkenstädt, B., Roche, V., Lévi, F., Gould, P.D., Foreman, J., Halliday, K., Hall, A. and Rand, D.A. (2013). Inference on periodicity of circadian time series, Biostatistics.

Kastan, M.B. and Bartek, J. (2004). Cell-cycle checkpoints and cancer, Nature 432: 316-323.

Lahav, G., Rosenfeld, N., Sigal, A., Geva-Zatorsky, N., Levine, A.J., Elowitz, M.B. and Alon, U. (2004). Dynamics of the p53-Mdm2 feedback loop in individual cells, Nature Genetics 36: 147-150.

Loewer, A., Batchelor, E., Gaglia, G. and Lahav, G. (2010). Basal dynamics of p53 reveal transcriptionally attenuated pulses in cycling cells, Cell 142: 89-100.

Ma, L., Wagner, J., Rice, J.J., Hu, W., Levine, A.J. and Stolovitzky, G.A. (2005). A plausible model for the digital response of p53 to DNA damage, Proceeding of the National Academy of Sciences of the United States of America 102: 14266-14271.

Sun, T., Yang, W., Liu, J. and Shen, P. (2011). Modeling the basal dynamics of p53 system, PLoS One 6: e27882.

Wade, M., Wang, Y.V. and Wahl, G.M. (2010). The p53 orchestra: Mdm2 and Mdmx set the tone, Trends Cell Biology 20: 299-309.

Yu, T., MacPhail, S.H., Banath, J.P., Klokov, D. and Olive, P.L. (2006). Endogenous expression of phosphorylated histone $\mathrm{H} 2 \mathrm{AX}$ in tumors in relation to DNA double-strand breaks and genomic instability, DNA Repair (Amst) 5: 935-946. 